\title{
The Determinants of Health Care Utilization among the Elderly in a Rural Community in Northern Nigeria
}

\author{
${ }^{1}$ Oluwabunmi Grace Ibitoye, ${ }^{2}$ Olutobi Adekunle Sanuade, ${ }^{3}$ Ayo Stephen \\ Adebowale, ${ }^{4}$ Olusola Ayeni \\ ${ }^{I}$ Nigeria Social Insurance trust Fund (NSITF), Abuja, Nigeria* \\ ${ }^{2}$ Regional Institute for Population Studies, University of Ghana Accra, Ghana \\ ${ }^{3,4}$ Department of Epidemiology \& Medical Statistics, Faculty of Public Health, College of Medicine, University \\ of Ibadan, Ibadan, Nigeria.
}

\begin{abstract}
The study examined the determinants of health care utilization among the elderly in Ijumu local government area of Kogi State Nigeria. The study was cross-sectional in design. A multi-stage sampling technique was adopted and 1217 elderly aged 65+ were randomly selected. Health care utilization was operationalized as whether the respondent sought biomedical treatment or not when they took ill. Data were analysed using descriptive statistics and binary logistic regression. The mean age of the elderly was $72.3 \pm 8.4$ years and a larger proportion was females. About $59 \%$ were in monogamous family and more than one-third were living with chronic conditions. Socio-economic status, types of family and living with chronic conditions were the determinants of biomedical health care utilization. An increase in socio-economic status increased the odds of seeking biomedical treatment, and those in polygamous family were more likely to seek biomedical health treatment. Those living with chronic conditions had higher odds of seeking biomedical treatment compared to those with no chronic illness. Since the elderly seems to use biomedical health care, there is need for the government to ensure that the health care services are accessible and affordable for them, most especially for those living with chronic conditions.
\end{abstract}

\section{Background}

Population aging has been considered one of the most important demographic phenomena globally. This is because of the projected increase in the number of elderly populations which is due to decrease in fertility, mortality and an increase in life expectancy [1,2]. In 2010, the number of people aged 60 years and above globally was approximately 770 million. This is projected to increase to one billion by 2020 and about one-fifth of these people will be concentrated in developing countries [3]. Currently, the number of people who are 65 years and above has continued to increase by approximately 9 million people per year [4]. This projected increase has implication for rise in health cost because of the different health conditions associated with aging [2]. A large body of research has described the process of aging using different perspectives: demographic characteristics, physical health, cognitive impairment, disability and self-perceived health of older people in developed countries $[5,6,7]$.

Even though aging has been a challenge in the developed countries, it is gradually becoming a common phenomenon in developing countries despite limited access to health care, malnutrition, and low income. Changes in the aging process within developing countries, particularly Africa, have been observed through shifts in population age composition. This process is associated with rapid decline in fertility and mortality observed in the past few decades [8] . As a result, in the near future, older populations will become ubiquitous in Africa $[9,10,11]$. Further, in Africa, many older people reach retirement age after a lifetime of poverty and deprivation, poor access to health care and poor dietary intake. These situations leave them with insufficient personal savings $[12,13]$. In this region, growing old is so feared and reviled that people are prepared to undergo extreme torture in the quest to delay or possibly reverse the process.

In Nigeria, the number of the elderly population has been gradually increasing. The most recent census held in 2006 showed that the country has a total population of 140,431,790 million, of whom $9.5 \%$ are aged 50 years and over and $4.3 \%$ aged 65 years and over and the absolute number of people entering the older cohort is increasing [14]. Despite the increasing number of elderly population in Nigeria, the health care system spends a small fraction of the budget on treating the elderly and their access to care is limited. Also, providing health care for this people is not a policy priority $[15,16]$. Further, the attitude of health care providers towards older people makes their situation even more difficult. It has been shown that the elderly in Nigeria are frequently mistreated by health care providers when they seek care [17]. Many of these people may not access health services due to inability to provide their age, aggravated by the limited availability of health services, equipment and expertise. Further, current health challenges and existing policies act to hide the situation of older people. As a result, 
some of these people resort to ethno-medical treatment, faith healing or self-drug administration whenever they fall sick [17].

Even though a lot of studies on aging have been done in Asia and Latin America, there has been limited research on aging and its impact on the health and well-being of older people in Nigeria, especially in rural settings where people are mostly beset by poverty and poor health conditions. The study examines the determinants of health care utilization of older people in Ijumu local government area of Kogi State Nigeria.

\section{Study Area}

\section{Methodology}

The study was carried out at Ijumu Local Government Area (LGAs) of Kogi State. The Local Government is unique in terms of common language and cultural values. Ijumu Local Government area has a population of 119,929 , of which $64,547(53.8 \%)$ were males and 55,382 (46.2\%) were females [13]. It was made up of three administrative districts namely; Gbede district in the North, Ijumu-Arin or Ijumu central and Ogidi/Ijumu-Okedistrict in the south. There were fifteen political wards in all with five in Gbede district, four in Ijumu-Arin district and six in IjumuOke district. Also, there were 740 enumeration areas with 340 in Gbede district, 261 in Ijumu-Arin and 149 in Ijumu-Oke [14].

\section{Sample Design}

This was a cross-sectional study of 1217 elderly people (65 years and above) residing in Ijumu Local Government Area for at least a year. The study was limited to the elderly who had resided in the community for at least one year so as to reduce bias that could occur as a result of influx of elders who are either visitors or who have enjoyed facilities in the cities or their previous place of residence.

\section{Sampling Technique}

A multistage sampling technique was adopted. One political ward was randomly selected from each of the 3 districts in the Local Government. Thereafter, simple random sampling technique was used to select one community out of the constituent communities of each ward. House numbering at community level was done with each house having a unique number and 40 households were randomly selected using table of random numbers. After this, 10 households were randomly selected from each of the selected households using balloting. One elderly was interviewed per household and in houses having more than one eligible persons, a respondent was picked using lottery method.

\section{Dependent Variable}

\section{Measures}

Health care utilization was operationalized as whether the respondent sought biomedical treatment or not. Hence, anyone who sought biomedical treatment was coded as " 1 " and " 0 " otherwise. Use of other health care services like ethno-medical, faith healing and self-drug administration were collapsed as not seeking biomedical care because they were not significantly different from each other.

\section{Independent Variable}

The independent variables included age, sex, marital status, socio-economic status, religion, occupation, type of family, ethnicity and whether the respondents were living with chronic conditions or not. At the multivariate analysis, a principal component factor analysis was used to compute the socio-economic status. The variables that were used included level of education and employment status. The output shows that the two items loaded on one factor and so measure the same latent variable called "socio-economic status" (Marital status was re-coded into two categories namely: single and married. This is because those who were never married and those formerly married were not significantly different from each other.

\section{Methods of Analysis}

The data were analyzed using STATA 12. Simple descriptive statistics and binary logistic regression were carried out. Binary logistic regression was used to identify the determinants of health care utilization.

\section{Background Characteristics}

\section{Results}

Table 1 presents the descriptive statistics of the respondents. The mean age was $72.3 \pm 8.4$ years. A larger proportion were females $(65.2 \%)$ and more than seven out of ten $(71.3 \%)$ were currently married. More than half had no formal education while about 6.6 percent had higher education. Approximately, $70 \%$ were Christians. About $61 \%$ were currently working and a larger proportion of those who were working engaged in 
agricultural related activities. In addition, more than (59.2\%) were in monogamous family and about $96 \%$ were Yoruba.

\section{Health Conditions and Health Care Utilization}

Table 2 shows the health conditions and health care utilization of the respondents. About $70 \%$ were recently sick and nearly everybody sought treatment when they took ill (97.7\%). Also, more than one-third of the respondents $(35.2 \%)$ were living with chronic health conditions. About one-tenth had eye defects and general body pain (10.9\% and $9.5 \%$ respectively). Less than one out of ten of the elderly had fever, depression, ulcer and cough. Table 3 shows the type of health care utilization for those who sought treatment when they were ill. Out of those who sought treatment when they took ill, a larger proportion $(91.2 \%)$ reported the use of biomedical health care while the least proportion used faith healing $(0.8 \%)$.

\section{Determinants of Health Care Utilization}

The result of the binary logistic regression is shown on Table 4. Socio-economic status, types of family and living with chronic conditions were found to be the significant determinants of biomedical healthcare utilization. The model shows that controlling for other variables, a unit change in socio-economic status increased the odds of seeking biomedical treatment by $80.5 \%$. Compared to those in polygamous family, those who were in monogamous family were about $47 \%$ less likely to seek biomedical treatment when other variables were controlled for. Further, the odd of seeking biomedical treatment was $167 \%$ higher for those living with chronic conditions compared to those with no chronic conditions.

\section{Discussion}

The study found that socio-economic status is one of the determinants of biomedical health care utilization among the elderly in Nigeria, and this is consistent with other studies $[17,18]$. This indicates that as socio-economic status increases, the tendency to seek biomedical health care also increases. This is expected because receiving biomedical treatment demands availability of money needed to settle the health care bills. Without this, receiving biomedical treatment will be difficult most especially in Nigeria where the National Health Insurance Scheme (NHIS) does not function well. The implication of this is that people who have lower SES will be disadvantaged in terms of their ability to seek biomedical treatment. It is important therefore that access should be provided for those with lower SES either by subsidizing health care services or make the NHIS more functional.

The study further showed that those who were leaving with chronic conditions had higher odds of seeking biomedical treatment. This is very logical knowing that chronic diseases cannot be cured but can only be maintained and so require frequent medical treatments. However, studies have shown that many of the people living with chronic diseases visit the hospital for diagnosis but use ethno-medical or faith healing in maintaining the diseases $[19,20]$. Hence, elderly in Ijumu Local Government living with chronic conditions may have sought biomedical treatment because of the belief that the illness is biologically caused and so require biomedical treatment. The implication of this is that it is important to ensure that appropriate medications are available to treat chronic conditions at biomedical health centres in this local government. Further, since the cost of treating chronic condition is very huge, there may be need to subsidize these medications in order to make them accessible by the elderly. This is owed to the revelation of several studies that the poor usually finds it difficult to access medications for their chronic conditions and even the rich can also become poor because of the cost of treating these conditions [20,21].

In addition, this study shows that those in the monogamous family were less likely to use biomedical health. One plausible explanation for this is that compared to elderly in polygamous family, those in monogamous family may have less pool of resources in terms of their ability to afford biomedical health care bill.

\section{Conclusion}

The study shows that socio-economic status, types of family and living with chronic conditions are predictors of biomedical health care utilizations at Ijumu Local Government Area, Nigeria. Although the findings may not be generalizable to the whole of Nigeria, the findings are relevant to elderly at Ijumu Local Government. The implication of our findings is that because of the decreasing income for the elderly, free health care services may be made available so as to further increase health care utilizations most especially for those living with chronic conditions. 


\section{References}

[1]. Palloni A, Pinto-Aguirre G, Pelaez M. Demographic and health conditions of ageing in LatinAmerica and the Caribbean. International Journal of Epidemiology, 2003; 31:762-771.

[2]. González-González C, Sánchez-García S, Juárez-Cedillo T, Rosas-Carrasco1 O,Gutiérrez-Robledo LM and García-Peña C. Health care utilization in the elderly Mexican population: Expenditures and determinants. BMC Public Health, 2011; 11:192.

[3]. U.S. Census Bureau, Population Division: International Data Base 2010. [http://www.census.gov/ipc/www/idb/estandproj.pdf].

[4]. Mukherjee D and Patil CG. Epidemiology and the Global Burden of Stroke.Wolrd Neurosurgery, 2011;76(6):585-590.

[5]. Riley JC. The Timing and Pace of Health Transitions around the World.Population and Development Review, 2005;31(4):741-764.

[6]. Xie J, Mathews FE., Jagger C, Bond J, and Brayne C. The oldest old in England and Wales: a descriptive analysis based on MRC cognitive function and ageing study. Age and Ageing, 2008;37:396-402.

[7]. Xu X, JG. Health effects of managed care among the near older persons. Journal of Aging Health, 2008;18:507.

[8]. Kinsella K. and Wan H.An Aging World.United States Census Bureau, International Population Reports, 2009; P95/09-1.U.S. Government Printing Office, Washington, DC.

[9]. United Nations. Socio-Economic Status and Living Arrangements of Older Persons around the world ST/ESA/STAT/SER.A/240.New York: United Nations 2005,

[10]. United Nation. World population prospects: the 2000 revision. New York: United Nations, 2001.

[11]. Mba CJ. Nigeria's Ageing Population: A Call for Attention. Journal of the International Institute on Ageing, 2001;12(1):15-24.

[12]. Charton K E. and Rose D. Nutrition among older adults in Africa the situation at the beginning of the millennium. Journal of Nutrition, 2001;131:245-85.

[13]. Kimokoti R W and Hamer D H. Nutrition, health, and aging in sub-Saharan Africa. Journal of Nutrition, 2008;66: 611-23.

[14]. National Population Commission (NPC), Nigeria.Final results of 2006 Census. Official Gazette of 2nd February, 2009. Abuja, Nigeria: National Population Commission 1-327.

[15]. Poullier J P, Hernandez P, and Kawabata K. Health systems performance assessment: debates, methods, and empiricism. In: Evan s ICJLMADR, (ed). National health accounts: concepts, data sources, and methodology. Geneva: World Health Organization, 2003:185-93.

[16]. Tollman S, Doherty J, Mulligan J A. General primary care: Disease control priorities in developing countries. Washington, DC: International Bank for Reconstruction and Development and the World Bank, 2006:1193-209.

[17]. Abdulraheem I S. Health needs and determinants of health seeking behaviour among elderly Nigerian: a household survey. Annals of African medicine, 2007; 6(2): 58-63.

[18]. Ahmed SM, Tomson G, Petzoid M, Kabir ZN. Socioeconomic status override age and gender in determining health-seeking behaviour in rural Bangladesh.WHO Bulletin, 2005; 83:109-117 .

[19]. Hjelm K and Mufunda E. Zimbabwean Diabetics' Beliefs about Health and Illness: An interview Study. BMC International Health and Human Rights, 2010;10(7):1-10.

[20] Nguma LK. Health Seeking and Health Related Behaviour for Type 2 Diabetes Mellitus among adults in an Urban Community in Tanzania. A thesis submitted to the University of Otago, New Zealand, 2010.

[21]. Frenk J, José LB, Claudio S, Tomas F, Rafael L. Elements for a theory of the health transition. Health Transition Review, $1991 ; 1 ; 21-38$.

[22]. Agyei-Mensah S and de-Graft AA. Epidemiological transition and the double burden of disease in Accra, Ghana. Journal of Urban Health, 2010: Bulletin of the New York Academy of medicine;87(5):879-897.

List of Tables

Table 1: Background Characteristics of Respondents

\begin{tabular}{|c|c|c|}
\hline Characteristics & Frequency & Percentage \\
\hline Mean Age & 1217 & $72.3(8.4)$ \\
\hline \multicolumn{3}{|l|}{ Sex } \\
\hline Male & 424 & 34.8 \\
\hline Female & 793 & 65.2 \\
\hline \multicolumn{3}{|l|}{ Marital Status } \\
\hline Never Married & 20 & 1.6 \\
\hline Currently Married & 868 & 71.3 \\
\hline Formerly Married & 329 & 27.1 \\
\hline \multicolumn{3}{|l|}{ Level of Education } \\
\hline No education & 641 & 52.7 \\
\hline Primary & 355 & 29.2 \\
\hline Secondary & 140 & 11.5 \\
\hline Higher & 81 & 6.6 \\
\hline \multicolumn{3}{|l|}{ Religion } \\
\hline Christian & 843 & 69.3 \\
\hline Muslim & 369 & 30.3 \\
\hline Traditional & 5 & 0.4 \\
\hline \multicolumn{3}{|l|}{ Employment Status } \\
\hline Working & 737 & 60.6 \\
\hline Not working & 480 & 39.4 \\
\hline \multicolumn{3}{|l|}{ Occupation } \\
\hline Professional & 11 & 1.5 \\
\hline Sales and Services & 268 & 36.4 \\
\hline Skilled manual & 45 & 6.1 \\
\hline
\end{tabular}




$\begin{array}{lcc}\text { Unskilled manual } & 125 & 17.0 \\ \text { Agriculture } & 288 & 39.0 \\ \text { Family Type } & & 59.2 \\ \text { Monogamy } & 708 & 40.8 \\ \text { Polygamy } & 489 & \\ \text { Ethnic Group } & & 0.6 \\ \text { Hausa } & 7 & 96.4 \\ \text { Yoruba } & 1,173 & 0.7 \\ \text { Igbo } & 8 & 2.3 \\ \text { Others } & 29 & \end{array}$

Note: Number in parenthesis is the standard deviation

7.0

39.0

59.2

40.8

0.6

96.4

2.3

Table 2 Health Conditions of the elderly

\begin{tabular}{lcc}
\hline \hline & $\mathrm{N}=1217$ & \\
\hline \hline Variable & Frequency & Percentage \\
\hline \hline Sick Recently & & \\
Yes & 851 & 69.9 \\
No & 366 & 30.1 \\
Sought treatment & & \\
Yes & 831 & 97.7 \\
No & 20 & 2.3 \\
Health Conditions & & \\
Chronic Diseases & 428 & 35.2 \\
Eye defects & 133 & 10.9 \\
Body Pain & 115 & 9.5 \\
Fever & 93 & 7.6 \\
Depression & 71 & 5.8 \\
Ulcer & 51 & 4.2 \\
Cough & 25 & 2.1 \\
\hline
\end{tabular}

Table 3: Health Care Utilization

\begin{tabular}{lcc}
\hline \hline & $\mathrm{N}=831$ & \\
\hline \hline Health Care Utilization & Frequency & Percentage \\
\hline \hline Biomedical & 758 & 91.2 \\
Ethnomedical & 29 & 3.5 \\
Faith healing & 7 & 0.8 \\
Self administration & 37 & 4.5 \\
\hline
\end{tabular}

Table 4:Determinants of Health Care Utilization

\begin{tabular}{lcc}
\hline \hline Characteristics & Odds Ratio & Standard Error \\
\hline \hline Sex & & \\
Male (RC) & 1.4077 & \\
Female & & 0.5719 \\
Marital Status & & \\
Single & 1.1169 & 0.4299 \\
Currently married & & \\
Age & &
\end{tabular}




\begin{tabular}{lcc} 
Age & 1.0252 & 0.0316 \\
SES & & \\
Socio-Economic Status & $1.805^{+}$ & 0.6264 \\
Religion & & \\
Christianity & 0.8455 & 0.289 \\
Islam/traditional & & \\
Occupation & & \\
Agriculture & 0.5094 & 0.4132 \\
Professional/Skilled & 0.6507 & 0.2497 \\
Sales/services & 2.167 & 1.420 \\
Unskilled manual & & \\
Type of family & & \\
Polygamy & $0.5299^{+}$ & 0.1901 \\
Monogamy & & \\
Ethnicity & & \\
Hausa/Igbo & 0.7792 & \\
Yoruba & & \\
Chronic condition & & \\
No & & \\
Yes & $2.6718^{*}$ & \\
\hline Note: $*^{p}<.05^{+}<^{* 01}$ & & \\
& & \\
\hline
\end{tabular}

Note: ${ }^{*} \mathrm{p}<.05{ }^{+} \mathrm{p}<.01$ 